\title{
Role of Cone Beam Computed Tomography in Dentistry
}

\author{
Ruchi Juneja ${ }^{1 *}$, Akshat Gupta ${ }^{1}$, Sombir Singh ${ }^{2}$, and Varun Kumar ${ }^{3}$ \\ ${ }^{1}$ Senior Resident, PGIMER, Chandigarh \\ ${ }^{2}$ Senior Resident, PGIMER, Chandigarh \\ ${ }^{3}$ Varun Kumar, Endodontic Consultant, Faces $n$ Smiles Dental Clinic, Chandigarh
}

Received: September 10, 2016; Accepted: September 17, 2016; Published: September 25, 2016

*Corresponding author: Ruchi Juneja, MDS, Conservative Dentistry \& Endodontics, Ex-Senior Resident, PGIMER, Chandigarh, \#3115, Sector 38-D, Tel: +91-9501172632; Email: ruchijuneja1986@gmail.com

\begin{abstract}
Cone Beam Computed Tomography (CBCT) is a three dimensional imaging tool which has emerged as a major diagnostic aid in dentistry in a very short span of time. By its ability to capture intricate maxillofacial hard tissues with sub-millimeter spatial resolution, it has revolutionized the process of diagnosis in dentistry. Significantly reducing the radiation exposure in comparison to conventional CT scans, it has found its place in all dental specializations. Compact design, as it has, makes it suitable for small clinical practices as well. This article illustrates how CBCT can help in establishing a diagnosis by providing additional information in various conditions of general and specialized dentistry.
\end{abstract}

Keywords: Cone beam computed tomography; Diagnosis; Radiography; Three dimensional imaging

\section{Introduction}

The science of dentistry has been continuously seeking to improve the performance of diagnostic aids available in this specialty. Intra oral periapical radiographs and panoramic radiographs have been the mainstay of radiographic diagnosis in all specialties of dentistry [1]. Although both are indispensable to dentistry, but the amount of useful information yielded by these is limited by accompanying superimposition of various anatomic structures. Three dimensional CT scan imaging and MRI imaging has been considered only in limited number of patients till date, because of the larger size of machines which can't be accommodated in a dental office and thus necessitates referral. Their use has been limited because of unacceptably high radiation dose for routine dental care. CBCT has, therefore emerged as an alternative aid and is widely gaining popularity at a rapid rate all over the world.

Cone beam technology was introduced to markets in 1996 by QR s.r.l. (New Tom 9000) [2]. This revolutionary technology has brought a paradigmatic shift in dental radiology. Though introduced as a tool in dentistry, CBCT has found numerous applications in other medical fields, mainly interventional radiology as well. It is widely used to identify the correct location of artery for chemoembolization in hepatocellular carcinoma [3], prostate artery embolisation in benign prostate hypertrophy [4], during placement of intracranial and extracranial stents
[5], abscess drainage, adrenal vein sampling for adenoma [6], identification of tissue infarcts in vascular anomalies and many other medical uses. The purpose of this article is to discuss and highlight the diagnostic applications of CBCT in various specialties of dentistry by means of a few cases which benefitted from its use.

\section{Oral and maxillofacial surgery}

The ability to depict all anatomic structures without superimposition by buccal and lingual structures makes CBCT an immensely useful guide in oral and maxillofacial surgeries. It is superior to panoramic radiography for localization of inferior alveolar canal in relation to impacted third molar because this canal frequently follows a tortuous path and hence, may not be reliably interpreted on a two dimensional image [7] (Figure 1A). Similarly, interpreting the buccolingual relationship of an impacted canine in relation to lateral incisor is much simpler with CBCT (Figure 1B), which otherwise requires multiple obliquely angled IOPA views and occlusal views [8]. Ankylosis of impacted teeth is also more reliably visualized on CBCT and hence, the treatment difficulty can be timely anticipated [9].

CBCT also provides important information on the extent and location of cystic lesions and other benign lesions and sometimes aids in their detection which are otherwise missed (Figure 1C). The associated changes like presence and extent of bone resorption, cortical expansions, calcifications, bone sclerosis in surrounding bone etc. can also be visualized more predictably with sectional imaging as compared to that with conventional 2D images [10] (Figure 1D). This is because, since the effect of superimposition is removed, the internal structure or the surrounding structures can be visualized layer by layer; resulting in better interpretation. CBCT is, therefore, a very helpful tool for surgical planning of such cases, as full extent and relative proximity to various anatomic structures is assessed [11].

Moreover, malignant lesions can be differentiated from benign lesions by carefully studying the smoothness or irregularity of their margins and bone invasion pattern (Figure 1E). This can be revealed in early stages with sectional imaging. CBCT was found comparable to Multi-slice computerized tomography for studying the bone invasion pattern in malignancies [12]. MRI, however, still remains a better alternative for soft tissue tumour. 

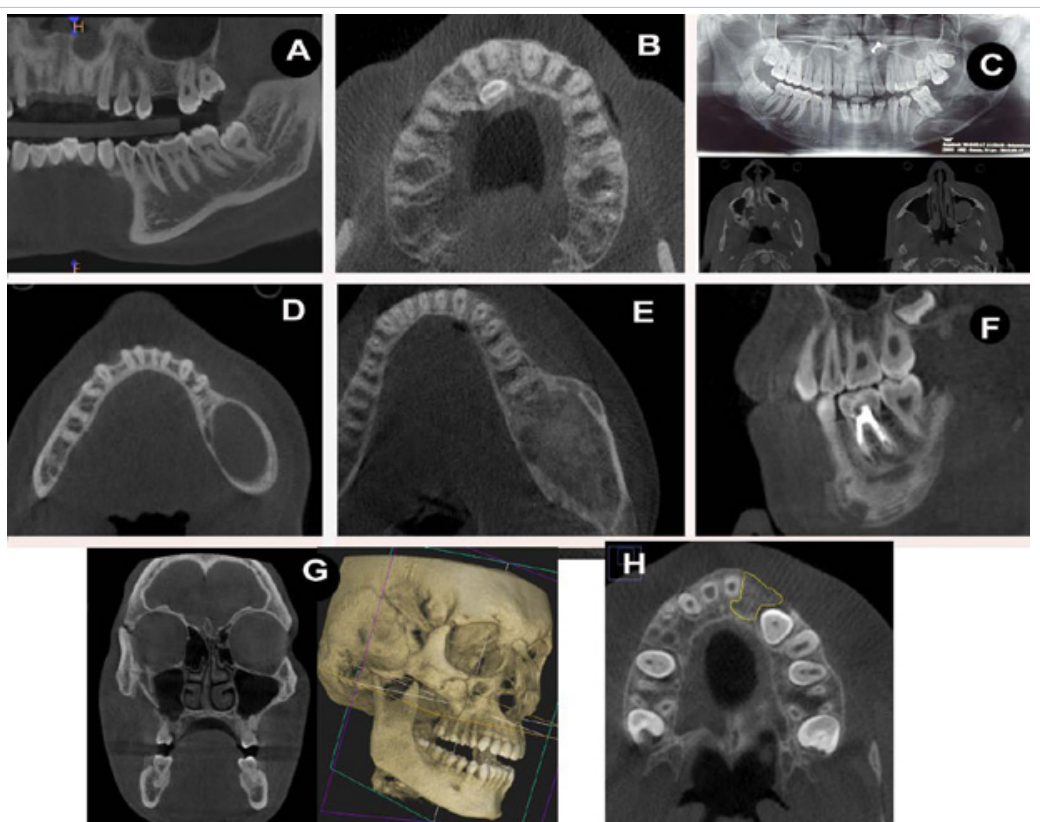

Figure 1: Uses of CBCT in Maxillofacial surgeries.

A: Section from CBCT showing exact location of inferior alveolar canal in relation to lower third molar.

B: Transverse section showing location of impacted canine palatal to rest of the arch.

C: Patient with multiple OKC. Cyst in left maxilla was not very clear in OPG. Transverse section reveals large cyst on left maxilla along with its extent into the sinus.

D: Cortical expansion due to $\mathrm{OKC}$ clearly evident in transverse section.

E: Ewing's sarcoma in mandible, evident with irregular margins and bone invasion pattern.

F: Periosteal bone reaction in osteomyelitis.

G: Fracture at FZ suture, zygomatic buttress and maxillary wall clearly evident.

$\mathrm{H}$ : Volume of cleft can be measured.

CBCT also provides a clearer vision of periosteal bone reaction in chronic inflammatory lesions as compared to occlusal and panoramic radiographs [13] (Figure 1F).

CBCT is a valid alternative imaging tool to MDCT for complex jaw fractures [14] (figure 1G). However for trauma patients with associated vertebral fractures or head injuries, MDCT and MRI are better alternatives. CBCT provides a deep insight into the cleft defect in cleft palate patients. The relation of cleft to dentition and nasal cavity can be thoroughly studied. Alveolar bone support of the teeth associated with cleft can be assessed [15]. The volume of cleft defect can be measured and hence, the amount of graft material needed to reconstruct the alveolus can be determined [16] (Figure 1H).

\section{Orthodontics}

Due to less superimposition and magnification error, and image distortion due to isometric voxel size used in CBCT, they are more accurate than 2-D cephalograms and panoramic radiographs. Although low FOV and medium FOV are useful in certain cases as in assessing individual impacted teeth or single jaw, most circumstances usually indicate the use of large volume CBCT in orthodontics to incorporate the skull bases, facial bones and dentition.

The use of digital casts, as prepared by CBCT has also been now introduced to orthodontics which can be used for measuring intra-arch parameters [17]. These digital models also reveal roots of the teeth and unerupted teeth, hence providing additional information like crown-root angulations and crown to root ratio.
Individual teeth can also segmentized in these casts and tooth movement can be simulated, and the outcome of extraction /non-extraction plan can be tested pre-operatively. Some software enhancements also allow creating a virtual patient, in which individually soft tissues, skeletal hard tissues or dental structures are enhanced to different extents, to simulate a threedimensional virtual patient like image (Figure 2A). These virtual patient images can then be used to simulate surgeries, facial asymmetry evaluation, digitized tooth movements to analyze results etc (Figure 2E). Volume of pharyngeal airway and changes in volume of pharyngeal airway space after mandibular setback surgeries can also be measured (Figure 2B)

Furthermore, CBCT has an immense application in treatment planning of cases with impacted teeth (Figure 2D). The exact location of tooth can be assessed and point of surgical exposure and the subsequent mechanics to be applied can be precisely planned. CBCT images also help in planning the site of temporary anchorage device placement as the thickness of bone at various possible sites, and distance between two roots can be accurately measured [18].

Post-orthodontic effects on dentition, like external apical root resorption (Figure 2C) or alveolar bone loss due to rapid palatal expansion (due to tipping of posterior teeth) can also be assessed more accurately with CBCT. CBCT images with voxel sizes ranging from 0.2-0.4 $\mathrm{mm}^{3}$ are better than 2-D radiographs for measuring small changes in root length due to apical root resorption [19].

Three-dimensional CBCT scans are more reliable and 

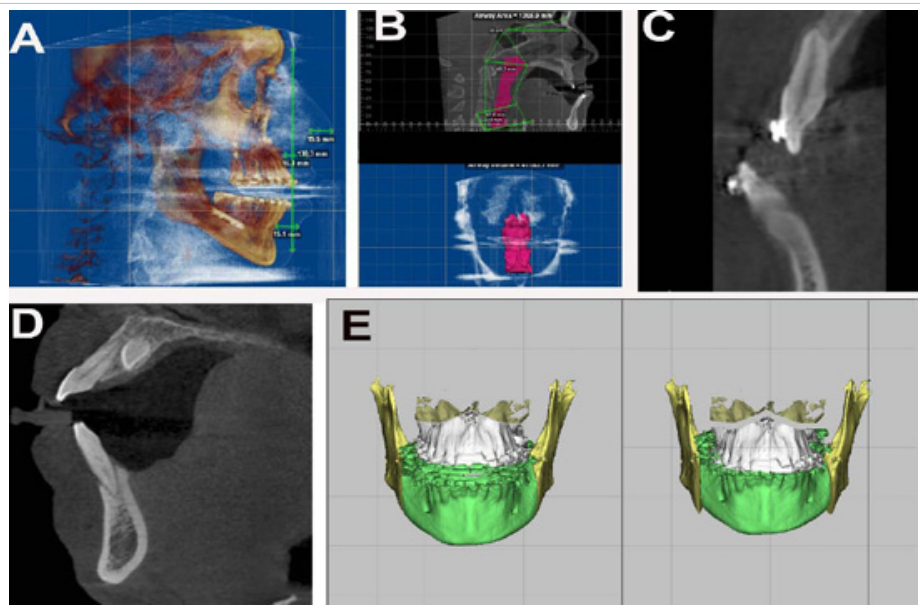

Figure 2: Uses of CBCT in orthodontics.

A: CBCT image enhanced with Dolphin software, both hard and soft tissue appreciated. B: Airway measurement with CBCT.

C: Apical root resorption due to orthodontics can be seen at very early stages.

C: Apical root resorption due to orthodontics can be seen at very early stages.
D: Exact location of crown of impacted teeth can be seen and point of surgical exposure can be planned.
E: Surgical simulation using CBCT with Dolphin software. Image on left is the preoperative image.

Image on right shows planned surgical result (Maxillary advancement $6 \mathrm{~mm}$ and mandibular set back $7 \mathrm{~mm}$ ).

accurate for detection of mandibular asymmetry than lateral cephalographs [20]. This is because chances of error due to varying distance of structure to film are not present and the anatomic landmarks are more clearly identifiable. Nevertheless, the accuracy of linear and angular measurements performed on CBCT-synthesized cephalograms is similar to conventional lateral cephalograms [21]. CBCT images may also be sensitive to orientation of head during scan.

Many orthodontically based software programs are now available for clinical use, e.g. SICAT Function and JMT, 3dMDvultus Software, In Vivo Dental Software, Sure Smile Software, Insignia Software. These soft wares combine surface tracking with 3-D CBCT imaging and help in appliance fabrication, surgical planning, shaping of arch wires and much more. Thus, in orthodontics, CBCT is no longer a mere diagnostic entity, but a clinical and translational tool.

\section{Periodontics}

Intra-oral radiography is still the most commonly used technique for diagnosis of periodontal bone defects. Since the advent of CBCT in various fields of dentistry, various studies have been conducted to evaluate the potential of this technique in periodontics, and mixed results have been obtained. CBCT has been found to be accurate to sub millimeter levels in measuring horizontal bone loss [22]. Three dimensional quantitative information on periodontal bone levels has been reported to be slightly better than conventional radiography. However, the qualitative description of bone levels, i.e. bone quality and contrast was significantly better with conventional radiography [23].

The 3D images are more suitable for evaluating the infrabony defects (Figure 3). They offer a definitive advantage over radiographs in assessing bony defects on buccal and lingual walls. Misch et al. [24] reported that CBCT was found to be superior to periapical radiographs in detection of bony defects. However in interproximal areas, both radiographs and CBCT were equally reliable. CBCT images are also superior for analyzing the exact shape of the defect, location (buccal or lingual), and for furcation defects. In a study by Walter, et al. [25], CBCT was found to be most accurate for assessing disto-palatal furcations, followed by buccal and mesio-palatal maxillary molar furcation defects.

The ability of CBCT to detect earliest changes in periodontal disease, i.e. wedge shaped radiolucency in periodontal ligament space or a break in continuity of lamina dura, is proportional to the voxel size used. Jervoe-Storm, et al. [26] used a voxel size of $0.15 \mathrm{~mm}$ and found it to be sufficient to image PDL space changes. However, when the size of the gap was smaller than voxel size, detection of gap decreased. Various studies have reported that conventional radiographs are better than CBCT in assessing the periodontal ligament space [24-27].

The use of CBCT has also been reported for diagnosis of palatogingival groove [28]. It may also be a valuable assessment tool for assessment of periodontal regeneration outcomes.

\section{Temporomandibular joints}

Traditionally used two dimensional panoramic imaging and transcranial TMJ projections have limited reliability and sensitivity in detecting TMJ changes [29]. CT has been a valuable aid for hard tissue changes and MRI for disc assessment [30]. CBCT is a low cost and low dose alternative for CT. It can be used to evaluate the integrity of bony structures, to confirm the extent and stage of progression of disorder and to evaluate the effects of treatment [31].

CBCT has a capability to detect early changes in TMJ osteoarthritis like irregular cortical outlines, erosions, osteophyte formation, subchondral cyst formation, narrowing of joint space, flattening of articular surfaces and sub-chondral sclerosis [32,33]. Similar changes are also found in inflammatory disorders but to a 


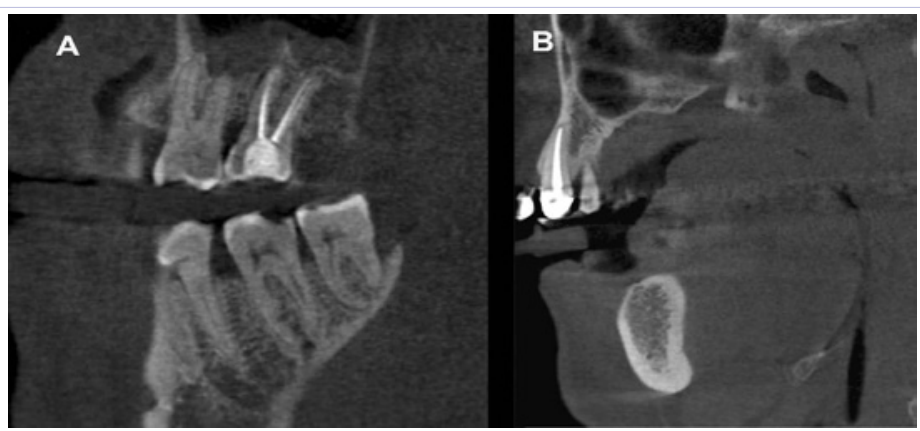

Figure 3: Use of $\mathrm{CBCT}$ in periodontics

A: Vertical bone defect in multirooted tooth

B: Vertical bone defect in single rooted tooth

larger extent. Presence of calcified loose bodies in a widened joint space and an irregular or sclerotic glenoid fossa on CBCT image points towards synovial chondromatosis (Figure 4A). Although the articular disc is not visualized in CBCT, but since disc derangements are often associated with osteoarthritic changes, CBCT findings may be sufficient to indicate an underlying disc derangement.

CBCT is increasingly been used as a routine modality for TMJ trauma and TMJ ankylosis (Figure 4B). The location of the fracture and relation of the fracture line to joint capsule, and the displacement of fracture can be well-demonstrated. However, hemarthrosis and capsular tears are better evaluated with MRI. CBCT is immensely helpful in establishing the diagnosis and classification of TMJ ankylosis. It helps in differentiating bony ankylosis from fibrous ankylosis and thus assists in treatment planning. It is also superior to panoramic radiographs in detecting coronoid hyperplasia and neoplastic lesions involving TMJ (Figure 4C). The uniform enlargement of condylar head in condylar hyperplasia can be distinguished from irregular condylar mass and altered trabecular pattern in osteochondroma can be differentiated using CBCT (Figure 4D). On the contrary, malignancies on CBCT examination show bone destruction with minimal expansion and erosive, ill-defined and irregular margins (Figure 4E, 4F). CT, MRI and PET scan constitute more advanced diagnostic measures to be used when malignancy is suspected on CBCT.

\section{Endodontics}

Superimposition has always been a problem in endodontic diagnostic and treatment radiographs. Multiple angled radiographs often require multiple radiographs to obtain the required information, increasing chairside time as well as patient discomfort; and still in many instances the interpretation remains doubtful. It is for this reason that CBCT was accepted rapidly by the endodontic community soon after its introduction to dentistry.

Apical periodontitis, an indication for endodontic treatment, can be identified at its incipience by means of CBCT (Figure 5A) [34]. The sensitivity of periapical and panoramic radiography for the detection of apical periodontitis is 0.55 and 0.28 respectively, whereas CBCT can be considered as a gold standard with a sensitivity of 1 [35]. Patel, et al. [36] reported with artificially created periapical lesions in human mandibles that $100 \%$ of the lesions were detected with CBCT.

Pre-operative determination of actual number of canals present in a tooth always remain an enigma even to experienced endodontists. CBCT reveals the true number, shape and exact location of the canals, where they divide or merge, including their portal of exit (Figure 5B). It is also invaluable for assessing endodontic architecture of teeth with unusual anatomy (Figure 5C). Pre-operative assessment of this otherwise unpredictable anatomy aids in providing a conservative treatment free of endodontic mishaps.

Similar to any surgery in maxillofacial region, pre-surgical assessment in periapical surgery is also being adapted as a routine now [37]. In mandibular molars, the proximity to the canals can be accurately detected [38]. In maxillary molars, it is particularly helpful in assessing the palatal roots [39]. The distance between the cortical plate and the palatal root apex can be measured, and the proximity to maxillary sinus or nasal floor can be assessed (Figure 5D, 5E) [38]. The presence of isthmuses can be identified [40]. The amount of remaining supporting alveolar bone support can be assessed, and the need for grafts and membranes can be judged pre-operatively. In multi-rooted teeth, the actual root to which the lesion is associated can be identified and hence a more conservative treatment can be planned (Figure 5E) [41]. The inclination of roots can be viewed which helps in both the location of the apex; and correct angulation of apicoectomy [41]. Differentiation of periapical granuloma from cyst has also been attempted and promising results have been obtained [42]. This is possible because of differences in grey scale value measurements of cystic and non-cystic type lesions.

CBCT is particularly useful in diagnosis of dentoalveolar trauma which otherwise requires multiple angled radiographs [43]. The exact nature and severity of alveolar and luxation injuries can be assessed from just one scan. Being an extraoral technique, it is much more feasible and comfortable than intraoral radiographs in recently traumatized patients; and offers multifold better information than otherwise resorted panoramic radiographs in such situations. Horizontal and oblique root fractures can be accurately assessed [44]. 

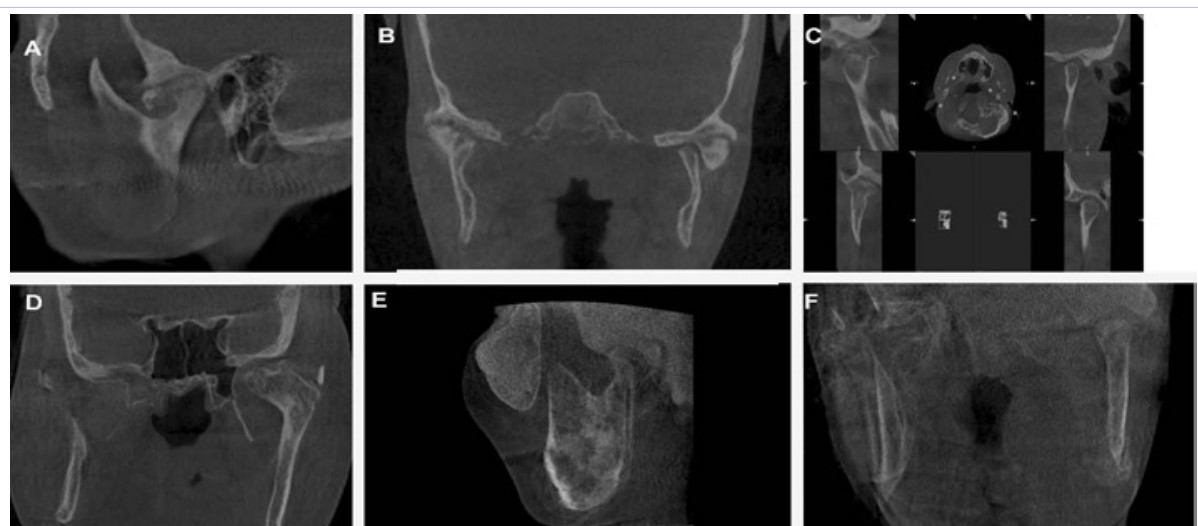

Figure 4: Use of CBCT in Temporomandibular joint pathologies.

A: Calcified loose body in synovial chondromatosis of TMJ.

B: TMJ ankylosis on right side TMJ and condyle fracture on left side TMJ.

C: Condylar hyperplasia right condyle.

D: Osteochondroma left condyle.

E\&F: Ewings Sarcoma involving right condyle and ramus.
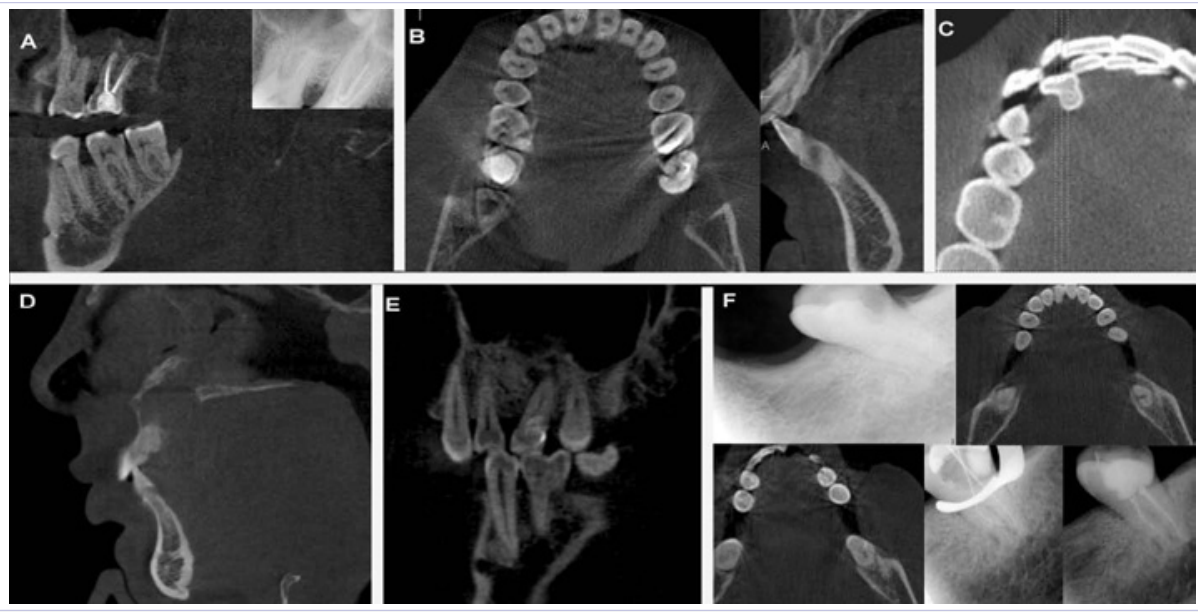

Figure 5: Uses of CBCT in endodontics. A: Periapical widening evident in mesiobuccal root of \#26 missed on IOPA view.

B: Transverse view showing an additional palatal canal in tooth \#21. Saggital view showing the canals merge in middle third.

B: Transverse view showing an additional palatal canal in tooth \#21. Sag

C: Complex root canal anatomies like dens invaginatus can be visualized.

D: Peripaical pathology i.r.t. \#22 showing communication with nasal cavity.
E: Periapical pathology associated with palatal root of \#26, close to maxillary sinus cavity.

F: C shaped canal system visualized with the help of CBCT in a lower second molar with calcified canals. CBCT assisted in location of canal openings.

Additional areas where importance of CBCT is being studied include location of narrow canal space in pulp canal obliteration cases (Figure 5F), location of lateral canals and assessment of treatment outcome [45].

\section{Implantology}

American Academy of Oral and Maxillofacial Radiology, in 2000, recommended that some form of cross-sectional imaging should be used for radiographic examination of any potential implant site [46]. Further, in 2012, they recommended that CBCT should be considered as the imaging modality of choice for preoperative imaging of potential implant sites [47].

CBCT allows for the determination of available bone height, width and quality (Figure 6A). Vertical bone height, width and saddle length need to be matched with the number and physical dimensions of implants (Figure 6B). Linear measurements with $\mathrm{CBCT}$ are precise without any magnification, hence this assessment is better done with CBCT than medical CT [48]. Bone quality depends on cortical and trabecular bone which is required to hold the implant securely. Evaluation of bone mineral density is gaining interest to assess bone quality. Studies are under way to depict the potential of CBCT to accurately assess bone quality and indicate that CBCT may yield structural analysis of trabecular bone soon [49].

The 3D topography of the alveolar ridge can also be accurately determined, i.e. presence or absence of lingual undercut, location of mylohyoid ridge and ridges which are selectively resorbed buccally or lingually after extraction. Separate thickness of buccal and lingual cortical plates can be measured. Proximity to anatomic structures like inferior alveolar canal, mental foramen, incisive canal, maxillary sinus and nasal cavity floor can be assessed presurgically.

CBCT is also being integrated with various softwares for surgical guidance, assess post-operative results presurgically; 

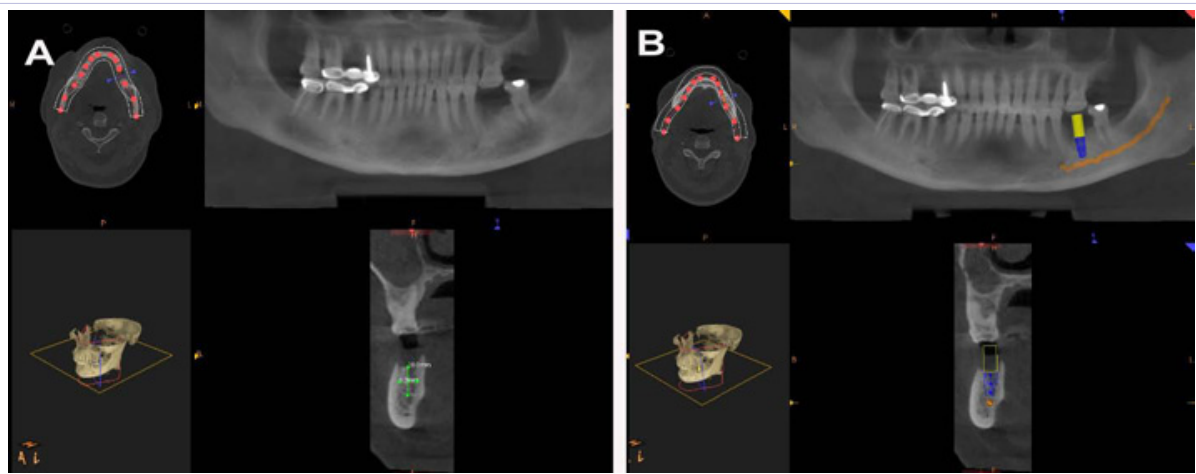

Figure 6: Role of CBCT in implant plannin

A: Detrmination of bone height and width.

B: Matching of bone height and width with implant height and width; Proximity to inferior alveolar canal accurately assessed.

and to create virtual patients where virtual implants can be placed and assessed. Such softwares also serve to fabricate surgical guides that can be used at the time of implant placement; and also aid in crown fabrication [50].

AAOMR recommends to consider the use of CBCT when clinical conditions indicate a need for augmentation procedures or site development before placement of dental implants, particularly in cases of ramus or symphysis grafting, sinus augmentation or other block or particulate bone grafting [47]. The use of СВCT is also recommended to evaluate previous augmentation procedures or to assess impacted tooth at site of implant placement. However, CBCT is advisable for post-operative evaluation of implants only if patient presents with severe mobility or altered sensation. In other cases, intraoral radiography is superior over CBCT in terms of better resolution and absence of beam hardening and streak artifacts. CBCT should also be considered in failure cases if implant retrieval is anticipated.

\section{Pedodontics}

CBCT finds its potential applications in pedodontics in multiple conditions; as in monitoring tooth development, impacted and supernumerary teeth, TMJ disorders, root resorption, traumatic injuries, craniofacial anomalies, orthodontic assessment, and cleft patients [51]. However, optimizing the exposure parameters is much more significant in paediatric patient than an adult patient. Machine systems with small field of view and child patient setting are better suited for pediatric patients. If small FOV system is not available, vertical and horizontal collimation should be offered. As child patients have a longer age span to manifest any radiation induced injury, the use of CBCT in pediatric patient should be fully justified on risk vs benefit scale [52].

\section{Conclusion}

CBCT overcomes a number of limitations of conventional imaging modalities. A judicious use of this technique should result in more accurate diagnosis and more precise treatment provided to the patients. However, owing to higher radiation doses and high initial cost of the equipment than the two dimensional imaging, it cannot serve as a substitute of the two dimensional imaging. Potential benefits must outweigh the higher costs and radiation hazards involved and, the indications must be defined keeping the above considerations in mind.

\section{References}

1. Vandenberghe B, Jacobs R, Bosmans H. Modern dental imaging: a review of the current technology and clinical applications in dental practice. Eur Radiol. 2010;20(11):2637-55. doi: 10.1007/s00330010-1836-1.

2. Scarfe WC, Farman AG Sukovic P. Clinical applications of cone-beam computed tomography in dental practice. J Can Dent Assoc.2006;72:7580 .

3. Wallace MJ, Kuo MD, Glaiberman C, Binkert CA, Orth RC, Soulez G, et al. Three-dimensional C-arm cone-beam CT: applications in the interventional suite. J Vasc Interv Radiol. 2009;20(7 Suppl):S523-37. doi: 10.1016/j.jvir.2009.04.059.

4. Bagla S, Rholl KS, Sterling KM, van Breda A, Papadouris D, Cooper JM, et al. Utility of cone-beam CT imaging in prostatic artery embolization. J Vasc Interv Radiol. 2013 ;24(11):1603-7. doi: 10.1016/j. jvir.2013.06.024.

5. Benndorf G, Claus B, Strother CM, Chang L, Klucznik RP. Increased cell opening and prolapse of struts of a neuroform stent in curved vasculature: value of angiographic computed tomography: technical case report. Neurosurgery. 2006;58(4 Suppl 2):ONS-E380; discussion ONS-E380.

6. Georgiades CS, Hong K, Geschwind JF, Liddeell R, Syed L, Kharlip J, et al. Adjunctive use of C-arm CT may eliminate technical failure in adrenal vein sampling. IntervRadiol. 2007;18:1102-5.

7. Mizbah K, Gerlach N, Maal TJ, Bergé SJ, Meijer GJ. The clinical relevance of bifid and trifid mandibular canals. Oral Maxillofac Surg. 2012;16(1):147-51. doi: 10.1007/s10006-011-0278-5.

8. Serrant PS, McIntyre GT, Thomson DJ. Localization of ectopic maxillary canines- is CBCT more accurate than conventional horizontal or vertical parallax? J Orthod. 2014;41(1):13-8. doi: 10.1179/1465313313Y.0000000076.

9. Nematolahi $\mathrm{H}$, Abadi H, Mohammadzade Z, Ghadim MS. The Use of Cone Beam Computed Tomography (CBCT) to Determine Supernumerary and Impacted Teeth Position in Pediatric Patients: A Case Report. J Dent Res Dent Clin Dent Prospects. 2013;7(1):47-50. doi: 10.5681/ joddd.2013.008. 
10. Kaneda T, Minami M, Kurabayashi T. Benign odontogenictumours of the mandible and maxilla. Neuroimaging Clin N Am. 2003;13:495-507.

11. Prabhusankar, K Yuvaraj A, Prakash CA, Parthiban J, Praveen B. CBCT Cyst Lesions Diagnosis Imaging Mandible Maxilla. J ClinDiag Res 2014;8:ZD03-ZD05. doi: 10.7860/JCDR/2014/7547.4228.

12. Dreiseidler T, Alarabi N, Ritter L, Rothamel D, Scheer M, Zöller JE, et al. Acomparison of multislice computerized tomography, cone-beam computerized tomography, and single photon emission computerized tomography for the assessment of bone invasion by oral malignancies. Oral Surg Oral Med Oral Pathol Oral Radiol Endod. 2011;112(3):36774. doi: 10.1016/j.tripleo.2011.04.001.

13. Ahmad M, Jenny J, Downie M. Application of cone beam computed tomography in oral and maxillofacial surgery. Aust Dent J. 2012;57 Suppl 1:82-94. doi: 10.1111/j.1834-7819.2011.01661.x.

14. Shintaku WH, Venturin JS, Azevedo B, Noujeim M. Applications of conebeam computed tomography in fractures of the maxillofacial complex. Dent Traumatol. 2009;25(4):358-66. doi: 10.1111/j.16009657.2009.00795.x.

15. Suomalainen A, Åberg T, Rautio J, Hurmerinta K. Cone beam computed tomography in the assessment of alveolar bone grafting in children with unilateral cleft lip and palate. Eur J Orthod. 2014;36(5):603-11. doi: 10.1093/ejo/cjt105.

16. Amirlak B, Tang CJ, Becker D, Palomo JM, Gosain AK. Volumetric analysis of simulated alveolar cleft defects and bone grafts using cone beam computed tomography. Plast Reconstr Surg. 2013;131(4):8549. doi: 10.1097/PRS.0b013e3182818e4f.

17. Rangel FA, Maal TJ, Bergé SJ, Kuijpers-Jagtman AM. Integration of digital dental casts in cone-beam computed tomography scans. ISRN Dent 2012;2012:949086. doi: 10.5402/2012/949086.

18. Diniz-Freitas M, Seoane-Romero J, Fernández-Varela M, Abeleira MT, Diz P, Cadarso-Suárez C, et al. Cone beam computed tomoghraphy evaluation of palatal bone thickness for miniscrew placement in Down's syndrome. Arch Oral Biol .2015;60:1333-9. doi: 10.1016/j. archoralbio.2015.06.013

19. Ponder SN, Benavides E, Kapila S, Hatch NE. Quantification of external root resorption by low vs high resolution cone beam computed tomography and periapical radiography: A volumetric and linear analysis. Am J OrthodDentofacialOrthop. 2013;143:77-91. doi: 10.1016/j.ajodo.2012.08.023.

20. Moro A, Correra P, Boniello R, Gasparini G, Pelo S. Three-dimensional analysis in facial asymmetry: comparison with model analysis and conventional two-dimensional analysis. J CraniofacSurg. 2009;20:41722. doi: 10.1097/SCS.0b013e31819b96a5.

21. Oz U, Orhan K, Abe N. Comparison of linear and angular measurements using two-dimensional conventional methods and three-dimensional cone beam CT images reconstructed from a volumetric rendering program in vivo. DentomaxillofacRadiol. 2011;40:492-500. doi: $10.1259 / \mathrm{dmfr} / 15644321$.

22. Banodkar AB, Gaikwad RP, Gunjikar TU, Lobo TA. Evaluation of accuracy of cone beam computed tomography for measurement of periodontal defects: A clinical study. J Indian SocPeriodontol. 2015;19:285-9. doi: 10.4103/0972-124X.154176.

23. Vandenberghe B, Jacobs R, Yang J. Detection of periodontal bone loss using digital intraoral and cone beam computed tomography images: an in vitro assessment of bony and/or infrabony defects. DentomaxillofacRadiol. 2008;37:252-260. doi: 10.1259/ dmfr/57711133.
24. Misch KA, Yi ES, Sarment DP. Accuracy of cone beam computed tomography for periodontal defect measurements. J Periodontol 2006;77:1261-6.

25. Walter C, Weiger R, Zitzmann NU. Accuracy of three dimensional imaging in assessing maxillary molar furcation involvement. J ClinPeriodontol 2010;37:436-41. doi: 10.1111/j.1600051X.2010.01556.x.

26. Jervøe-Storm PM, Hagner M, Neugebauer J, Ritter L, Zöller JE, Jepsen $\mathrm{S}$, et al. Comparison of cone beam computed tomography and intraoral radiographs for determination of periodontal ligament in a variable phantom. Oral Surg Oral Med Oral Pathol Oral RadiolEndod. 2010;109:e95-101. doi: 10.1016/j.tripleo.2009.10.023.

27.Ozmeric N, Kostioutchenko I, Hägler G, Frentzen M, Jervøe-Storm PM. Cone-beam computed tomography in assessment of periodontal ligament space: in vitro study on artificial tooth model. Clin Oral Investig. 2008;12(3):233-9. doi: 10.1007/s00784-008-01868.

28. Crow HC, Parks E, Campbell JH, Stucki DS, Daggy J. The utility of panoramic radiography in Temporomandibular joint assessment. DentomaxillofacRadiol 2005;34:91-95.

29. Sinha VP, Pradhan H, Gupta H, Mohammad S, Singh RK, Mehrotra D, Pant MC, Pradhan R. Efficacy of plain radiographs, CT scan, MRI and ultra sonography in temporomandibular joint disorders. Natl J MaxillofacSurg. 2012;3:2-9. doi: 10.4103/0975-5950.102138.

30. Hussain AM, Packota G, Major PW, Flores-Mir C. Role of different imaging modalities in assessment of temporomandibular joint erosions and osteophytes: a systematic review. DentomaxillofacRadiol. 2008;37:63-71. doi: 10.1259/dmfr/16932758.

31. Honda K, Larheim TA, Maruhashi K, Matsumoto K, Iwai K. Osseous abnormalities of the mandibular condyle: diagnostic reliability of cone beam computed tomography compared with helical computed tomography based on an autopsy material. DentomaxillofacRadiol 2006;35:152-7.

32. Tsiklakis K, Syriopoulos K, Stamatakis HC. Radiographic examination of the temporomandibular joint using cone beam computed tomography. DentomaxillofacRadiol. 2004;33:196-201.

33. Barghan S, Tetradis S, Mallya SM. Application of cone beam computed tomography for assessment of the temporomandibular joints. Aus Dent J 2012;57:(1Suppl):109-118. doi: 10.1111/j.18347819.2011.01663.x

34. Lofthag-Hansen S, Huumonen S, Gro"ndahl K, Gro"ndahl H-G. Limited cone-beam CT and intraoral radiography for the diagnosis of periapical pathology. Oral Surg Oral Med Oral Pathol Oral RadiolEndod 2007;103:114-9.

35. Estrela C, Bueno MR, Leles CR, Azevedo B, Azevedo JR. Accuracy of cone beam computed tomography and panoramic radiography for the detection of apical periodontitis. J Endod 2008;34:273-9. doi: 10.1016/j.joen.2007.11.023.

36. Patel S, Dawood A, Mannocci F, Wilson R, Pittford T. Detection of periapical bone defects in human jaws using cone beam computed tomographyand intraoral radiography. IntEndod J 2009;42:507-15. doi: 10.1111/j.1365-2591.2008.01538.x.

37. Tsurumachi T, Honda K. A new cone beam computertized tomography system for use in endodontic surgery. IntEndod J 2007;40:224-32.

38. Bornstein MM, Lauber R, Sendi P, von Arx T. Comparison of periapical radiography and limited cone-beam computed tomography in mandibular molars for analysis of anatomical landmarks before apical 
surgery. J Endod 2011;37:151-7.

39. Rigolone M, Pasqualini D, Bianchi L, Berutti E, Bianchi SD. Vestibular surgical access to the palatine root of the superior first molar: "low-dose cone-beam" CT analysis of the pathway and its anatomic variations. J Endod 2003;29:773-5.

40. Pécora JD, Estrela C, Bueno MR, Porto OC, Alencar AH, Sousa-Neto MD, et al. Detection of Root Canal Isthmuses in Molars by Map-Reading Dynamic using CBCT images. Braz. Dent. J. 2013;24:569-74 .

41. Nakata $K$, Naitoh $M$, Izumi $M$, Inamoto $K$, Ariji E, Nakamura $H$ Effectiveness of dental computed tomography in diagnostic imaging of periradicular lesion of each root of a multirooted tooth: a case report. J Endod 2006;32:583-7.

42. Simon JH, Enciso R, Malfaz J-M, Roges R, Bailey-Perry M, Patel A. Differential diagnosis of large periapical lesions using conebeam computed tomography measurements and biopsy. J Endod 2006;32:833-7.

43. Dolekoglu S, Fisekcioglu E, Ilguy D, Ilguy M, Bayirli G. Diagnosis of jaw and dentoalveolar fractures in a traumatized patient with cone-beam computed tomography. Dent Traumatol. 2010;26:200-3.

44. Avsever H, Gunduz K, Orhan K, Uzun I, Ozmen B, Egrioglu E, et al Comparison of intraoral radiography and cone-beam computed tomography for the detection of horizontal root fractures: an in vitro study. Clin Oral Investig. 2014 Jan;18(1):285-92.

45. Venskutonis T, Plotino G, Juodzbalys G, Mickevičienē L. The Importance of Cone-beam Computed Tomography in the Management of Endodontic Problems: A Review of the Literature. J Endod 2014;40:1895-1901.
46. Tyndall DA, Brooks SL. Selection criteria for dental implant site imaging: a position paper of the American Academy of Oral and Maxillofacial Radiology. Oral Surg Oral Med Oral Pathol Oral RadiolEndod 2000;89:630-7.

47. Tyndall DA, Price JB, Tetradis S, Ganz SD, Hildebolt C, Scarfe WC, American Academy of Oral and Maxillofacial Radiology. Position statement of the American Acabdemy of Oral and Maxillofacial Radiology on selection criteria for the use of radiology in dental implantology with empahasis on cone-beam computed tomography. Oral Surg Oral Med Oral Pathol Oral Radiol. 2012;113(6):817-26. doi: 10.1016/j.oooo.2012.03.005.

48. Salem WS, Dahaba MM, Khalifa S. Precision of Measurements from Computed Tomography (CT), Cone Beam Computed Tomography (CBCT) and their Reformatted Images in Pre-Operative Implant Assessment. Int J Surg Res Pract 2014;1:004.

49. Hao Y, Zhao W, Wang Y, Yu J, Zou D. Assessments of jaw bone density at implant sites using 3D cone-beam computed tomography. Eur Rev Med Pharmacol Sci. 2014;18:1398-403.

50. Patel N. Integrating three-dimensional digital technologies for comprehensive implant dentistry. J Am Dent Assoc. 2010;141Suppl $2: 20 \mathrm{~S}-4 \mathrm{~S}$.

51. Dhillon JK, Kalra G. Cone beam computed tomography: An innovative tool in pediatric dentistry. J Paediatr Dent. 2013;2:27-31.

52. Theodorakou C, Walker A, Horner K, Pauwels R, Bogaerts R, Jacobs R. Jacobs R; SEDENTEXCT Project Consortium. Estimation of paediatric organ and effective doses from dental CT using anthropomorphic phantoms. Br J Radiol 2012;85:153-60. 